\title{
Mean Ventricular Rate by Electrocardiogram
}

National Cancer Institute

\section{Source}

National Cancer Institute. Mean Ventricular Rate by Electrocardiogram. NCI Thesaurus.

Code C119263.

The calculated average rate of ventricular depolarisation as measured and recorded by an electrocardiog raph during a specified, extended period of time, and which is usually expressed in beats per minute. 